\title{
A INFORMAÇÃO COMO VANTAGEM COMPETITIVA NO PROCESSO LOGÍSTICO INTEGRADO NOS SERVIÇOS TURÍSTICOS
}

\author{
THE INFORMATION AS COMPETITIVE ADVANTAGE IN THE \\ PROCESS OF INTEGRATED LOGISTICS IN TOURISM SERVICES
}

\author{
Sara Joana Gadotti dos ANJOS - $\underline{\text { sara@ univali.br }}$ \\ Francisco Antonio dos Anjos - anjos@ univali.br \\ Ovidio Fellipe Pereira da Silva Júnior - ofellipe@univali.br \\ Professores e Pesquisadores da Universidade do Vale do Itajaí - UNIVALI
}

\section{RESUMO}

Em todos os setores da economia a competição está cada vez mais acelerada, pois tecnologicamente as organizações podem alcançar o mesmo patamar. Particularmente na gestão de serviços, o diferencial está na forma estratégica de utilização da informação, na obtenção da vantagem competitiva, proporcionando as organizações novas formas de superar o desempenho dos competidores, transformando toda a cadeia e tendo como foco as atividades de valor. Este artigo esta centrado na delimitação de um modelo de Gestão Integrada - SIGESTur, tendo a hotelaria como ponto central do processo de articulação entre os elementos que integram o sistema de turismo. Num primeiro momento, se aprofundam as discussões temáticas tendo por base a análise bibliográfica. Em um segundo momento, se desenvolve uma proposta metodológica tendo por base a análise bibliográfica e num terceiro momento se apresenta o modelo proposto. Para o desenvolvimento do modelo proposto fez-se uso de um estudo de caso em um hotel de rede nacional e 12 empresas parceiras (alimentação, lazer, entretenimento e meios de transporte), que fazem parte da rede de valor. Após a realização das entrevistas foram modelados os processos da rede de valor dos serviços turísticos, tendo como foco a identificação das articulações existentes entre o hotel e os demais serviços turísticos e por fim desenvolveu-se conceitualmente o modelo SIGESTUR. Os resultados da investigação apontam para uma cadeia de valor hoteleira cujo foco deve estar centrado num fluxo informacional eficiente e uma rede de valor alinhada com agilidade entre os parceiros logísticos do setor de turismo, inovando e agregando valor aos serviços ofertados.

Palavras-chave: Informação; Logística; Turismo.

\section{INTRODUÇÃO}

As atividades econômicas do turismo se tornam cada vez mais relevantes no cenário macro e micro-econômicos. O turismo se tornou o maior segmento na geração de empregos na escala mundial e a sua importância é percebida não só em nível econômico, mas também social, podendo contribuir na relação dos desequilíbrios 
regionais em um país e na melhoria da distribuição de renda (O'CONNOR, 2001; THEOBALD, 2001; SANCHO, 2001).

No cenário atual da economia mundial, uma das poucas certezas que temos é de que a sociedade está vivendo em um ambiente de permanente mudança. Capra (2002) enfatiza a necessidade das organizações passarem por uma mudança estrutural, tanto para se adaptarem aos novos cenários mundiais quanto para tornarem-se sustentáveis sob diversos pontos de vista. A informação está afetando a natureza da competição em todas as atividades econômicas, segundo Porter (1996), transformando-se em um poderoso recurso das organizações, permitindo um alinhamento estratégico através de fluxos com o ambiente externo (GONÇALVES; GONÇALVES FILHO, 1995).

A informação tem reconhecidamente grande importância no turismo, uma vez que o produto turístico é um serviço, e informações precisas, confiáveis e relevantes são essenciais para ajudar os viajantes a fazer uma escolha apropriada. A necessidade da informação está relacionada diretamente ao risco da compra. Este risco está ligado às características do produto.

Não se pode mais pensar na utilização da logística em serviços do mesmo modo que se utiliza com bens. Os serviços são intangíveis e em geral não homogêneos. Não se pode estocá-los e normalmente a produção é simultânea ao consumo. A logística de serviços precisa repensar a maneira que as organizações de serviço interagem com os consumidores (DAVIS; MANRODT, 1994). Um plano logístico deve abarcar essas peculiaridades e desenvolver estratégias para que elas ao invés de se tornarem barreiras, sejam utilizadas como um diferencial competitivo.

Com o objetivo de propor um modelo de Gestão Integrada dos Serviços Turísticos SIGESTur, tendo a hotelaria como ponto central do processo de articulação entre os elementos que integram o sistema de turismo, a pesquisa compreendeu dois momentos. Num primeiro momento num aprofundamento conceitual tendo como bases teóricas as discussões de: lógica das mudanças em Morgan (1996) e Capra (2002); conhecimento detalhado do funcionamento das organizações, particularmente em Bennett et al, (2001); informação como um recurso indispensável na agregação de valor ao produto final (serviço) em Lesca; Almeida, (1994); Laudon e Laudon, (1999); Vaitsman, (2001) e O'Connor, (2001); diferenciação dos serviços objetivando atender as inúmeras necessidades dos clientes, por Bovet; Thiagarajan (2000) e Hamel (2002); gestão por processos, sustentado por Grönroos (1998), Hammer (1998), Fitzsimmons e Fitzsimmons (2000) e Davenport (2002); gestão integrada dos serviços através de uma logística de valor de manutenção dos relacionamentos duradouros e lucrativos com os clientes, enfatizados em Bovet e Thiagarajan (2000), Hax e Wilde II (2000), Rogers (1998), Scavarda e Hamacher (2001), Bovet e Martha (2001); e processo de gestão integrada baseada no fluxo das informações e na comunicação entre empresa, fornecedores e clientes fundamentada em Normann e Ramirez (1993), Slack (1993), Poirer e Reiter (1997), Scavarda e Hamacher (2001), Bovet e Martha (2001), Ballou (2001), Pires (1998).

Num segundo momento, visando delinear o modelo proposto, fez-se uso de um estudo de caso (YIN, 2001), num hotel de rede nacional que possui um setor de relacionamento com o cliente que se configura como setor especializado de atendimento aos hóspedes. Também fizeram parte deste estudo de caso três empresas de cada segmento dos serviços turísticos (alimentação, lazer, entretenimento e meios de transporte), empresas que fazem parte do cadastro do setor de relacionamento do referido hotel e que possuem informalmente um maior relacionamento com o setor, bem como dois representantes do 
hotel pesquisado, totalizando 14 entrevistados. Para a realização das entrevistas semiestruturadas adotou-se um questionário como técnica de levantamento para a pesquisa empírica e suporte para as entrevistas. Após a realização das entrevistas foram modelados os processos de gestão do referido hotel e das doze empresas de serviços turísticos parceiras, tendo como foco a identificação das articulações existentes entre o hotel e os demais serviços turísticos e por fim desenvolveu-se conceitualmente o modelo de gestão integrada dos serviços turísticos.

Na concepção do modelo SIGESTur alguns pontos são considerados primordiais para a implementação da rede logística integrada, tais como características organizacionais, infra-estrutura tecnológica, gestão da informação, estratégias nos processos de serviços e a gestão integrada dos serviços propriamente dita. Tais fatos merecem uma longa deliberação entre o hotel e seus parceiros turísticos na implementação do modelo, de forma a proporcionar a inovação nos negócios por meio da combinação de esforços e aprimoramento mútuo e contínuo para assegurar a fidelidade dos hóspedes (ANJOS, 2004). A vantagem competitiva sobre os concorrentes somente será alcançada quando todas as oportunidades possíveis de aperfeiçoamento forem concebidas.

\section{GESTÃO DA INFORMAÇÃO E OS SERVIÇOS TURÍSTICOS}

O conjunto de produtos e serviços turísticos colocados à disposição em um determinado destino para o consumo e o desfruto do turista é também conhecido como oferta turística, que está diretamente relacionada à imagem geral do destino. E o conjunto complexo e inter-relacionado dos elementos da oferta turística faz parte do sistema turístico. Em geral estas atividades se relacionam de forma dinâmica. Um dos atuais desafios concentra-se na integração do processo de gestão dos serviços turísticos. Os meios de hospedagem e os serviços de alimentação possuem características comuns quanto a sua concepção conforme o tipo de estabelecimento, a sua exploração, o tipo de produto e sua comercialização, e também a aspectos como: costumes, estilo de vida, movimentos demográficos e pela economia nacional e internacional. A empresa hoteleira pode se colocar como elo de articulação entre os elementos que integram o sistema de turismo, pela sua atuação estratégica no sistema (Figura 1).

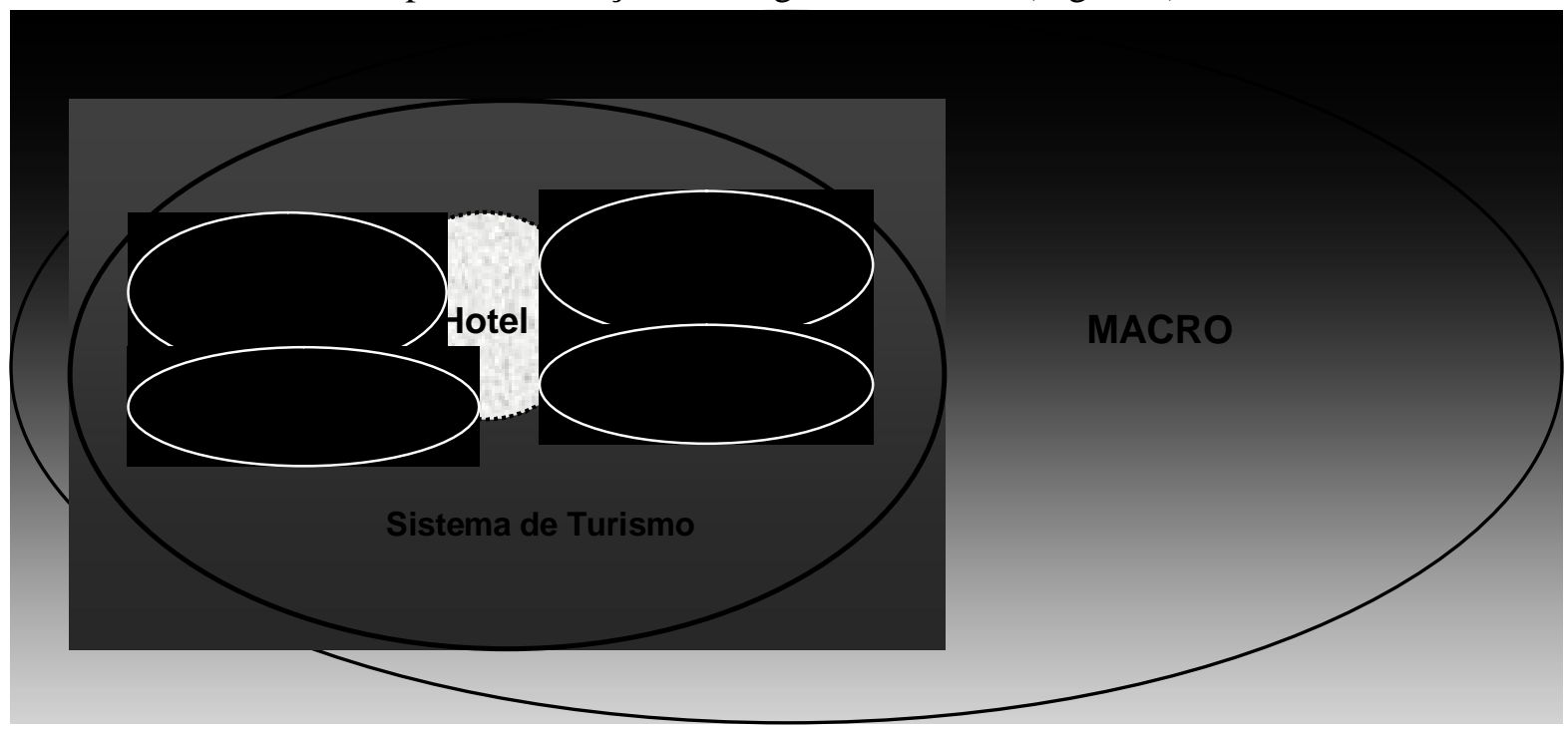

FIGURA 1: Representação do Sistema Integrado de Turismo. Fonte: Autores 
O produto turístico é um serviço, e como tal, intangível, não pode ser inspecionado ou experimentado antes da compra, dificultando a percepção do cliente quanto à qualidade do serviço ofertado. A diferenciação dos produtos e/ou serviços é uma das formas que as empresas vêm utilizando para satisfazer seus clientes e atrair novos negócios, aumentando a sua lucratividade. Para satisfazer as necessidades dos clientes é necessário ter o foco no cliente, ouvir os seus interesses e as suas opiniões. Essas ações são cruciais para adequar os produtos e serviços aos anseios do cliente, e para desenvolver inovações para o setor do turismo (STERN, 1997; LORGE 1999; HAMEL, 2002).

O turismo no Brasil gera cerca de 2 milhões de empregos formais, com um fluxo de 11,8 milhões de turistas internos que se hospedaram em hotéis durante o ano de 2006 e o crescimento das viagens independentes pelo setor de lazer vem exigindo que as informações disponibilizadas sejam precisas e atualizadas, para auxiliar na decisão da compra do serviço, tanto antes da compra, quanto depois da chegada na destinação. Desta forma, as informações sobre os destinos devem estar relacionadas diretamente aos estilos dos viajantes (O'CONNOR, 2001; MENDES; TOLEDO, 2001).

Para as organizações prestadoras de serviços turísticos é de extrema importância compreender as expectativas e necessidades dos turistas. Cada vez mais especificidades estão sendo exigidas pelos clientes que estão buscando novas experiências e reduzindo a utilização dos pacotes padronizados. A gestão da informação vem ao encontro destes anseios de maneira direta, aumentando as operações dos hotéis, através de um contato direto com o cliente (LAUDON; LAUDON, 1999; MENDES FILHO; RAMOS, 2001).

Algumas fronteiras entre bens e serviços estão desaparecendo, pois tanto empresas manufatureiras como de serviços estão preocupadas com a fidelização do cliente, ou seja, com a manutenção de relações com o cliente, passando assim a combinar a entrega de bens com serviços facilitadores ou vice versa.

Cabe às organizações turísticas analisarem que processos geram maior lucratividade, articulando ações que visem vantagens competitivas. Muitas vezes, as condições favoráveis ao crescimento do volume de oportunidades encontram-se nos clientes já existentes. Desta forma, é necessário ater-se ao cliente, criando mecanismos para pressupor as suas necessidades (SLYWOTZKY, 1999; LORGE, 1999, GERTZ, 1999; ROGERS, 1998).

As mudanças pelas quais passam as organizações do setor hoteleiro fazem com que este setor já reconheça a importância da reestruturação de seus processos e a inovação da gestão estratégica da informação. As grandes redes hoteleiras vêm disponibilizando recursos financeiros para desenvolver e aperfeiçoar sistemas de informação (O'CONNOR, 2001). As pequenas organizações prestadoras de serviços turísticos precisam se concentrar na cooperação, na busca pela competitividade e lucratividade individual.

\section{GESTÃO INTEGRADA}

O conceito de gestão integrada surgiu no setor produtivo, com o termo em inglês SCM Supply Chain Management (gerenciamento da cadeia de produção), caracterizado por uma nova forma de gestão de toda a cadeia produtiva (BALLOU, 2001). "A logística tem a preocupação de proporcionar produtos e serviços onde eles são necessários e quando eles são desejados (BOWERSOX; CLOSS, 1996, p.3)".

Na definição da logística por sua vez, do Council of Logistics Management citado por Ballou (2001), é o processo de planejamento, implementação e controle do fluxo 
eficiente e economicamente eficaz de matérias-primas, estoque em processo, produtos acabados e informações relativas desde o ponto de origem até o de consumo, com o propósito de atender às exigências dos clientes. Este conceito substitui outras definições anteriores, em função da progressiva evolução dessa ciência e a inclusão da noção de cadeia de suprimento, da qual a logística passa a ser uma componente.

Segundo Scavarda e Hamacher (2001, p.202), a cadeia de suprimentos "é uma rede que engloba todas as empresas que participam das etapas de formação e comercialização de determinado produto ou serviço, que será entregue a um cliente final". A cadeia de suprimentos é classifica por Slack (1993), em três níveis, a rede interna, a rede imediata e a rede total. A rede interna é composta pelos fluxos de informações e matérias entre os setores e componentes diretamente relacionados com as operações internas da empresa. A rede imediata é formada pelos fornecedores e clientes imediatos da empresa, e por último a rede total, que compreende todas as redes imediatas da área industrial ou de serviços. Corroboram Poirier e Reiter (1997, p. 19) salientando que a forma mais moderna e eficaz para uma organização conduzir seus produtos e serviços é através de uma cadeia de abastecimento, que é definida pelos autores por um "[...] um sistema pelo qual as organizações entregam seus produtos e serviços a seus clientes". Este sistema se apresenta em forma de redes interligadas, cada uma com seus significados e componentes, com o objetivo de melhorar o processo pelos quais as organizações realizam suas entregas e serviços.

A adequação desses pontos fortalece a participação mútua entre todos os participantes da cadeia, desenvolve o compartilhamento das informações específicas, aumentando o elo entre empresas incorporando qualidade aos produtos e serviços e apresentando melhores maneiras de servir aos mercados.

Numa visão contemporânea, Shank e Govindaragam (1988) e Porter (1996), sugerem que a criação de uma cadeia de valores é a forma de explorar vantagens competitivas, por que tal modelo engloba gerenciamento do fluxo de produtos e informações e, também o gerenciamento das relações internas e externas das organizações. A análise de uma cadeia de valores incorpora todas as atividades projetadas e coordenadas, organizadas de forma a atender as expectativas dos clientes e, ao mesmo tempo, proporcionar vantagens competitivas à empresa. $\mathrm{O}$ funcionamento de uma rede de valor depende da existência de parcerias dinâmicas e da inter-relação entre seus componentes, vai além do simples fornecimento, trata-se da criação de valor (BOVET; MARTHA, 2001).

Outra abordagem é a cadeia de valor, uma visão mais moderna que inclui uma gama de conhecimentos, onde as correntes não ocorrem em seqüência, mas em constelações; a função dos negócios é envolver os clientes na criação de valores, tirando vantagem dos conhecimentos, especialidades e habilidades de cada membro do sistema de criação de valor (NORMAN; RAMIRES, 1993).

Uma logística de serviços eficiente pode aumentar o valor do serviço através de um aumento na satisfação e na lealdade do cliente e reduzir os custos de fornecimento (DAVIS; MANRODT, 1994; CHEUNG at al, 2006)

Enfim, empresas que querem sobreviver devem perseguir todo meio possível de melhoria de seus processos e buscar o aperfeiçoamento benéfico para qualidade, produtividade, custo e satisfação do cliente, pois o cliente adotou novos hábitos de compra que exigem que os fornecedores, fabricantes, distribuidores e varejistas trabalhem mais unidos em trazer um valor adicional à prática de consumo, particularmente em relação à seleção, inovação e atendimento. 


\section{MODELO SIGESTUR}

No cenário contemporâneo, as organizações se encontram em permanente mudança. Tais mudanças têm origem nos clientes mais exigentes, na internet e a tecnologia digital e na globalização que motiva a pressão competitiva. $\mathrm{O}$ início do processo de mudança perpassa pela satisfação do cliente que está a cada dia mais apreensivo pelo acesso rápido à informação. Nestes cenários de transformações radicais as organizações necessitam identificar que necessidades dos clientes determinam maior ganho, agregando valor aos serviços e ao mesmo tempo competitividade à organização.

Cada destinação possui uma gama de serviços turísticos, desde uma diversidade de quartos num hotel, até um motorista poliglota num passeio. Esta variedade de informações sobre os produtos e serviços deve ser disponibilizada ao seu público alvo: o turista.

Para se gerenciar toda esta informação é imprescindível avaliar e coordenar internamente as organizações. Este conhecimento aprofundado atinge os processos/atividades e pessoas de forma que se configure um sistema interligado/atento às necessidades dos clientes existentes quanto às exigências que o mercado impõe constantemente. Na medida em que o mercado muda constantemente, os processos e atividades e diretamente as pessoas que executaram estas ações na organização devem estar se reciclando e se re-adequando a estes cenários.

Detalhar os processos de negócios caracteriza-se em constantemente subsidiar as organizações na compreensão das atividades executadas, e na busca do aperfeiçoamento constante na prestação dos serviços.

Para enfrentar os desafios e oportunidades as organizações precisam posicionar-se de forma competitiva, obtendo vantagens frente à concorrência. Esta vantagem competitiva inicia-se pela administração das relações internas e externas das organizações, intensificando os pontos fortes com os clientes e fornecedores quanto ao fluxo de informações para a geração dos serviços que satisfaçam as necessidades e expectativas dos clientes constantemente. $\mathrm{O}$ fortalecimento dos pontos fortes implica na parceria com os demais serviços turísticos, se configurando num elo com os parceiros, para incorporar qualidade e inovação aos serviços e produtos ofertados.

Para o pleno êxito da gestão integrada dos serviços turísticos, as empresas hoteleiras e os demais serviços precisam focar no seu cliente de forma a procurar constantemente satisfazer sua necessidade e pela sua fidelização, estes esforços resultarão num intenso processo de troca de informações, intensificando a logística dos serviços turísticos na localidade.

A construção de um processo o de uma gestão integrada tem como foco principal o cliente. Neste processo o hotel e os demais serviços turísticos estarão interligados com o objetivo de melhorar os processos de serviços, inovando em seu ambiente de negócios. Os principais desafios estão centrados no tempo de resposta aos serviços disponibilizados e na melhoria da comunicação nos elos de todos os processos.

A adaptação destes desafios permitirá a participação integrada de todos os serviços turísticos, no compartilhamento das informações e na qualidade dos serviços, oferecendo maneiras distintas de servir o seu público alvo.

O processo de gestão integrada examina as ligações com os clientes e fornecedores, as atividades internas da organização e a gestão do fluxo de informações, internas e externas. O sucesso depende da uma parceria dinâmica e inter-relacionada que objetivam a criação de valor ao longo dos processos. 
Gestão Integrada dos Serviços Turísticos - SIGESTUR constitui-se para Anjos (2004, p.170) em:

Gerenciar de forma integrada na hotelaria as informações relativas aos hóspedes/clientes visando à articulação do hotel com os demais serviços turísticos, satisfazendo as expectativas e necessidades dos hóspedes/clientes e propiciando vantagem competitiva às organizações envolvidas.

Para possibilitar a articulação do hotel com os serviços turísticos é necessário gerenciar de forma integrada toda a cadeia produtiva. Os principais pontos a serem gerenciados (Figura 1) são: a) A Empresa Mãe - considerado o Hotel $(\mathrm{H})$; b) $\mathrm{O}$ cliente Turista/Cliente $(\mathrm{T})$; c) $\mathrm{O}$ processo - Relacionamento com os clientes (RC) e d) os parceiros - Serviços Turísticos (ST).

A empresa mãe (Hotel- H) propicia a integração na cadeia de valor envolvendo os hóspedes/clientes e os parceiros. Controla os pontos de contato, acessando as informações sobre o hóspede/cliente, alimentando e criando relacionamentos e obtendo a sua satisfação por meio de serviços turísticos integrados. Da mesma forma, gerencia os serviços turísticos para garantir rapidez e interação cliente/parceiros (Figura 2).

Esta integração visa configurar estrategicamente toda a cadeia, integrando melhor as suas atividades e desenvolvendo rápidos canais de comunicação entre os serviços turísticos e os hóspedes/cliente.

Para a implementação e desenvolvimento do Modelo de Gestão Integrada dos Serviços Turísticos - SIGESTUR são necessárias algumas delineações quanto a: características organizacionais, infra-estrutura tecnológica; gestão da informação; estratégias processos de serviços, gestão integrada dos serviços e proposta de ampliação dos processos.

a) Características Organizacionais

Um dos principais pontos do modelo proposto SIGESTUR se caracteriza inicialmente na forma em que as organizações envolvidas se preocupam com a "imagem organizacional". Tal imagem deve ser percebida pelo cliente através da confiança, lealdade, inovação e diferenciação nos serviços prestados. A imagem da organização está estreitamente relacionada com seus objetivos/metas, onde não perfaz somente a delineação da missão e os objetivos organizacionais, mas é essencial que, todos em seus diversos níveis, sejam: estratégico, tático e operacional compartilhe no planejamento/execução das ações para alcançar estes objetivos. Desta forma o hotel necessita de parceiros com os objetivos semelhantes que resultarão em processos internos (da organização) e externos (do sistema integrado das organizações) de melhoria contínua. 


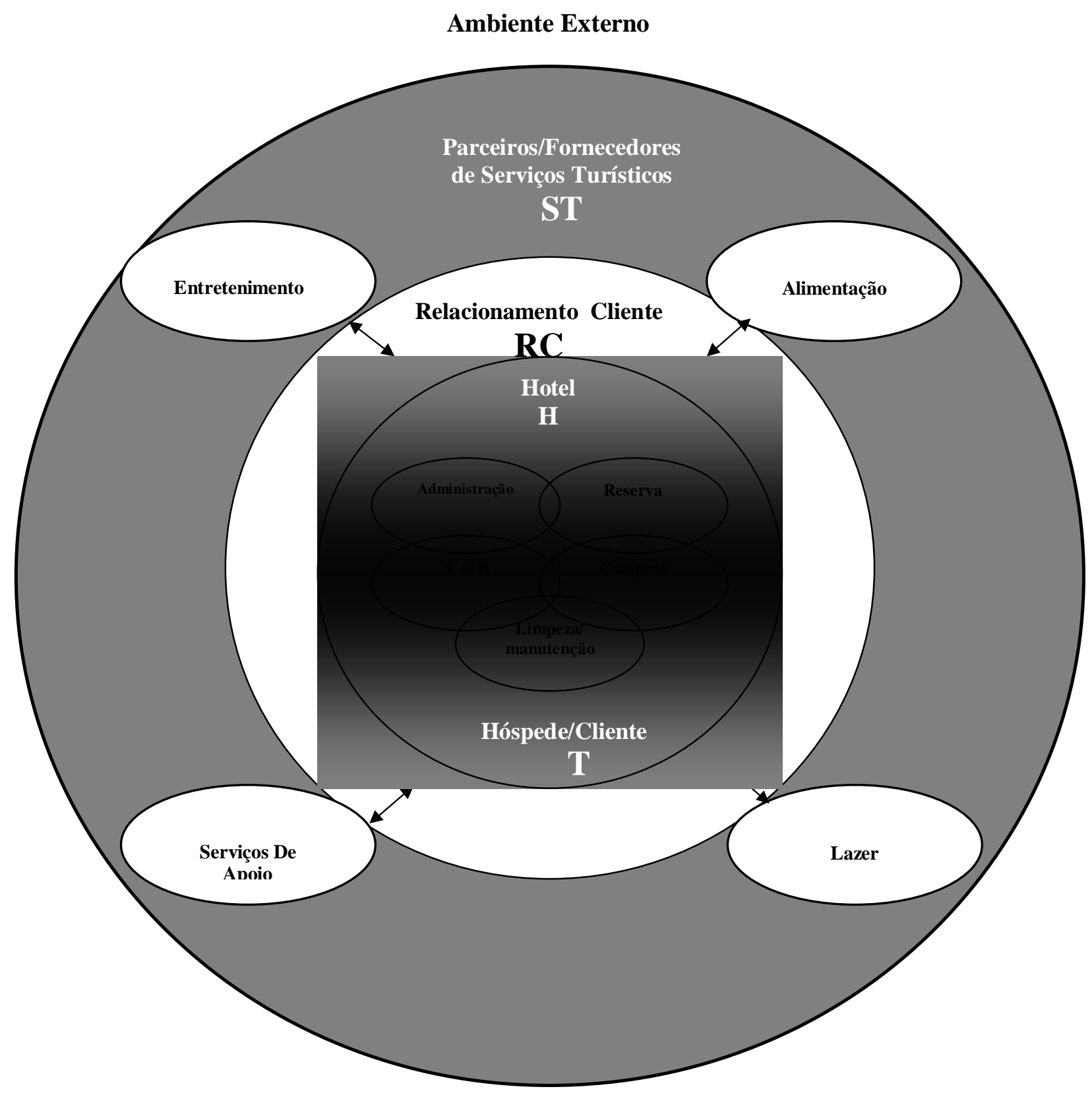

FIGURA 2: Gestão Integrada dos Serviços Turísticos - SIGESTUR Fonte: Autores

b) Infra-estrutura tecnológica

Para a integração do modelo SIGESTUR é necessário que as infra-estruturas tecnológicas estejam integradas entre os parceiros. As atividades dos processos internos devem agilizar os processos operacionais e as informações na organização de forma a abranger e integrar os serviços com acesso amplo a todos os níveis na organização. Constantemente é necessário planejar as estratégias tecnológicas, visando sempre 
atender/acompanhar as tendências do mercado e a percepção das necessidades dos hóspedes, mapeando constantemente as necessidades de cada setor.

O sistema do fluxo de informações e sua utilização inteligente se encontram na essência do SIGESTUR. Os caminhos das informações unem e coordenam as atividades internas na hotelaria com os hóspedes e demais serviços turísticos, possibilitando uma rápida tomada de decisões e um modelo de negócios competitivamente diferenciado.

c) Gestão da Informação

As organizações devem identificar constantemente as necessidades dos clientes/hóspedes que se constituem em informações valiosas, que podem contribuir no desenvolvimento de novos produtos ou serviços. Este processo deve ser estimulado pelo nível estratégico a toda organização, nos processos e nos procedimentos empresariais, de forma que também a gestão da informação faça parte da cultura organizacional de forma que de posse dos indicadores gerenciais, que serão acompanhados constantemente, visando medir os resultados dos processos para um constante o feedback.

O sistema do fluxo de informações e sua utilização inteligente se encontram na essência do SIGESTUR. Os caminhos das informações unem e coordenam as atividades internas na hotelaria com os hóspedes e demais serviços turísticos, possibilitando uma rápida tomada de decisões e um modelo de negócios competitivamente diferenciado.

d) Inovação dos Processos de Serviços

A inovação constante dos processos de serviços visando o atendimento das necessidades dos clientes, de forma a propor continuamente um diferencial frente à concorrência, a qualidade nos serviços e produto ofertados, desde que percebido pelo cliente é um diferencial de vantagem competitiva e permite que continuamente se ofereça algo inovador. Para inovar se devem mapear os principais grupos de clientes, de forma que o tratamento destinado aos diferentes grupos deve ser semelhante, mas buscando, contudo a personalização dos serviços/produtos.

e) Gestão Integrada dos Serviços.

O SIGESTUR é uma rede de parcerias dinâmica e de alto desempenho onde o hotel gerencia de forma integrada os clientes e os demais serviços turísticos.

O objetivo do Sistema Integrado SIGESTUR é proporcionar a inovação nos negócios por meio da combinação de recursos em uma ambiente concentrada no aprimoramento mútuo e contínuo para assegurar a fidelidade dos hóspedes. O hotel deve inicialmente começar descobrindo o que é importante aos seus diferentes clientes e refletir essa descoberta na articulação com os demais serviços turísticos/parceiros de forma a integrar um fluxo de informações. Desta forma é necessário que o hotel, faça uma avaliação das possibilidades reais de parcerias nos serviços turísticos, de modo que o SIGESTUR tenha valor e aplicação total para os hóspedes. Este sistema é marcado pelo relacionamento de confiança por meio dos quais os recursos valiosos são compartilhados para que as melhores soluções sejam encontradas.

As equipes tanto do Hotel $(\mathrm{H})$ quanto dos serviços turísticos (ST) deverão atuar com autonomia, de forma ágil e integrada, com constante aprimoramento, buscando permanente introdução de novos produtos e serviços e os esforços se tornem otimizados. A vantagem competitiva sobre os concorrentes é alcançada quando todas as oportunidades possíveis de aperfeiçoamento são implementadas.

Os recursos humanos envolvidos, tanto no hotel, quanto nos serviços turísticos deve ter por objetivo a cooperação voltada para a melhoria contínua dos processos, objetivos estes cruciais à sobrevivência e à preservação de uma vantagem competitiva. 
O dilema desse modelo é que sua implementação exige mudanças, deixar de considerar o sistema como algo conduzido pelo gerenciamento e passar a vê-lo como algo que funciona em resposta ao hóspede.

Para a implementação do SIGESTUR o hotel e seus parceiros terão entre outros benefícios, melhor competitividade, diferenciação/inovação e personalização nos serviços, buscando a satisfação das necessidades do cliente e a vantagem em relação à concorrência.

\subsection{O processo de relacionamento}

A gestão hoteleira é resumidamente composta pelos seguintes processos: Administrativo, Reservas, Alimentos e Bebidas, Compras e Limpeza e Manutenção (SILVA, 1999). A proposta do SIGESTUR caracteriza-se pela ampliação dos processos hoteleiros objetivando o incremento do processo de relacionamento com os demais processos internos e com os parceiros dos serviços turísticos (Figura 3).

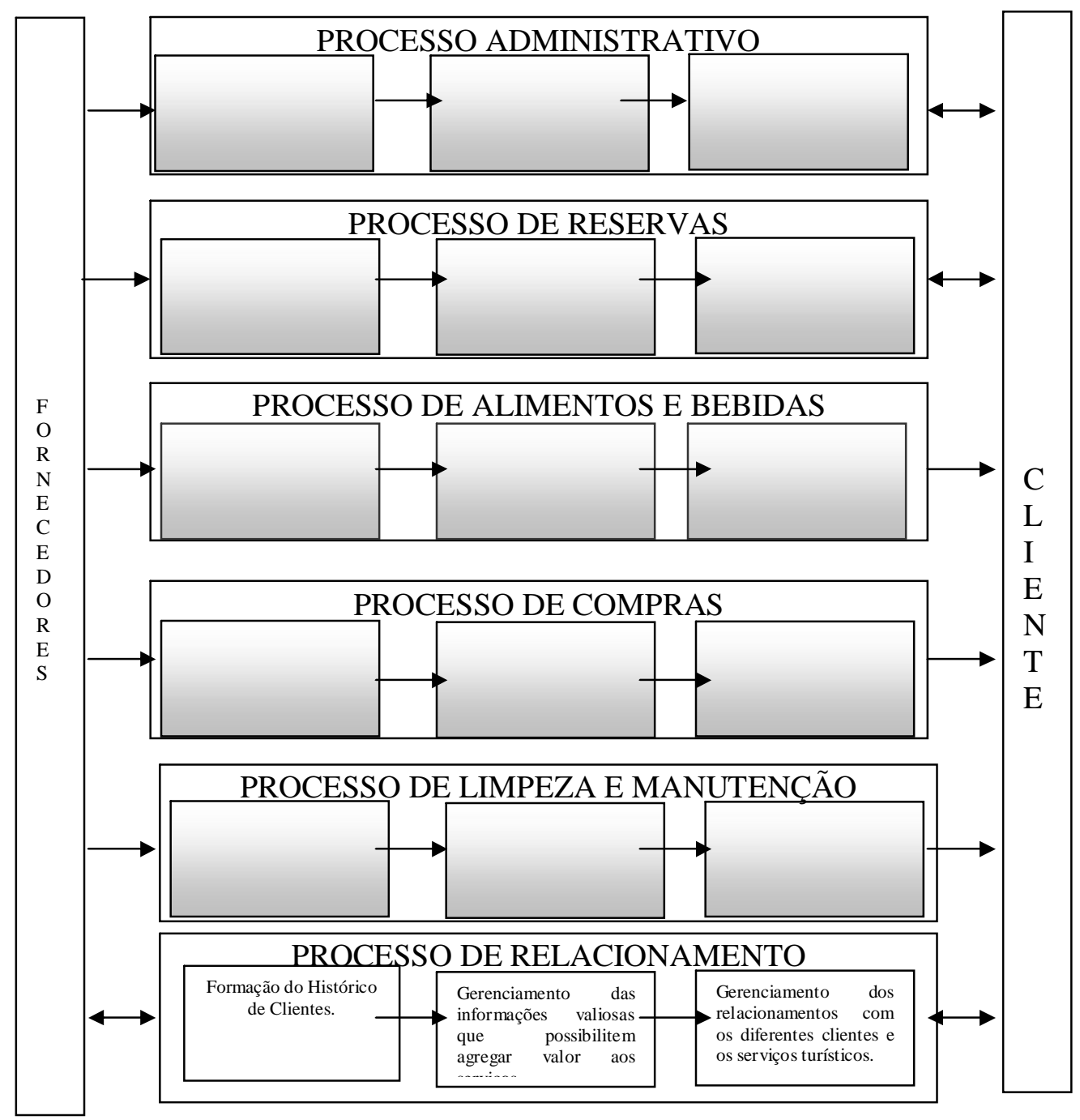

FIGURA 3. Processo da Cadeia de Relacionamento Hoteleiro. Fonte: Autores 
As atribuições do processo de relacionamento se constituem em: formação do histórico de clientes; gerenciamento das informações valiosas que possibilitem agregar valor aos serviços e gerenciamento dos relacionamentos com os diferentes grupos de clientes e os serviços turísticos.

A primeira atividade do processo de relacionamento se constitui na formação do histórico de clientes, e se caracteriza pelo mapeamento e identificação das informações das preferências e necessidades de cada hóspede individualmente.

A atividade permite a interação de forma operacional e gerencial dos demais processos internos, desde o administrativo, de reservas, de alimentos e bebidas, de compras e de limpeza e manutenção, gerando informações fidedignas das necessidades dos hóspedes, favorecendo o alinhamento dos processos hoteleiros com o perfil e desejo do cliente.

A segunda atividade do processo de relacionamento se constitui no gerenciamento das informações valiosas, e se caracteriza pela busca de agregar valor aos serviços. Essa atividade permite focar as necessidades específicas de hóspedes lucrativos, fortalecendo os laços de fidelidade, permitindo agregar valor aos serviços, ampliando a lucratividade e reduzindo a complexidade dos processos. Ressalta-se que o conhecimento detalhado das necessidades reais dos clientes (demanda) possibilita a redução ou eliminação dos custos gerados por atividades repetitivas ou que não agreguem valor, como estoques de alimentos e bebidas. O sistema funcionará de forma adequada somente quando os demais processos possuírem acesso às informações, criando possibilidade de inovações no ambiente de negócios.

A terceira atividade se constitui no gerenciamento dos relacionamentos com os diferentes grupos de clientes e os serviços turísticos, e se caracteriza pela integração das necessidades dos hóspedes às possibilidades dos serviços oferecidos pelas empresas parceiras. As parcerias nos serviços turísticos são formadas pelas empresas que se adequar ao perfil dos hóspedes e as estratégias do hotel, possibilitando que todas as empresas parceiras direcionem suas estratégias as necessidades dos hóspedes. Esta integração proporciona a personalização dos serviços oferecidos, o fornecimento de serviços com qualidade superior, criando condições para agregar de valor no processo. O gerenciamento dos relacionamentos possibilita a geração de relações duradouras do hotel com as suas empresas parceiras e os seus hóspedes. A vantagem competitiva será obtida quando as parcerias descobrirem todas as oportunidades de aperfeiçoamento possíveis desse processo.

O processo de relacionamento do hotel deve ter como meta constante o aperfeiçoamento do fluxo de informações, assim como da melhoria contínua da comunicação entre parceiros e clientes. As necessidades dos hóspedes devem ser atendidas de forma ágil, confiável e eficiente. A qualidade dos serviços oferecidos está diretamente relacionada à fidedignidade das informações relevantes, ou seja, as reais necessidades do hóspede. Enfim, o processo de relacionamento deverá beneficiar tanto o hotel quanto os parceiros, e em primeira instância os clientes.

Da mesma forma que o hotel, cada empresa parceira deverá introduzir um processo de relacionamento junto aos seus processos gerenciais. A inclusão desse novo processo visa somar esforços para perseguir os mesmos objetivos: satisfazer as necessidades dos hóspedes. As atribuições dos processos de relacionamento das empresas de alimentação, de lazer, de entretenimento de transporte são constituídas pelas atividades de: difusão das informações dos empreendimentos aos parceiros de relacionamento, integração das estratégias gerenciais com o foco no cliente e retro alimentação dos processos executados - feedback (Figura 4). 


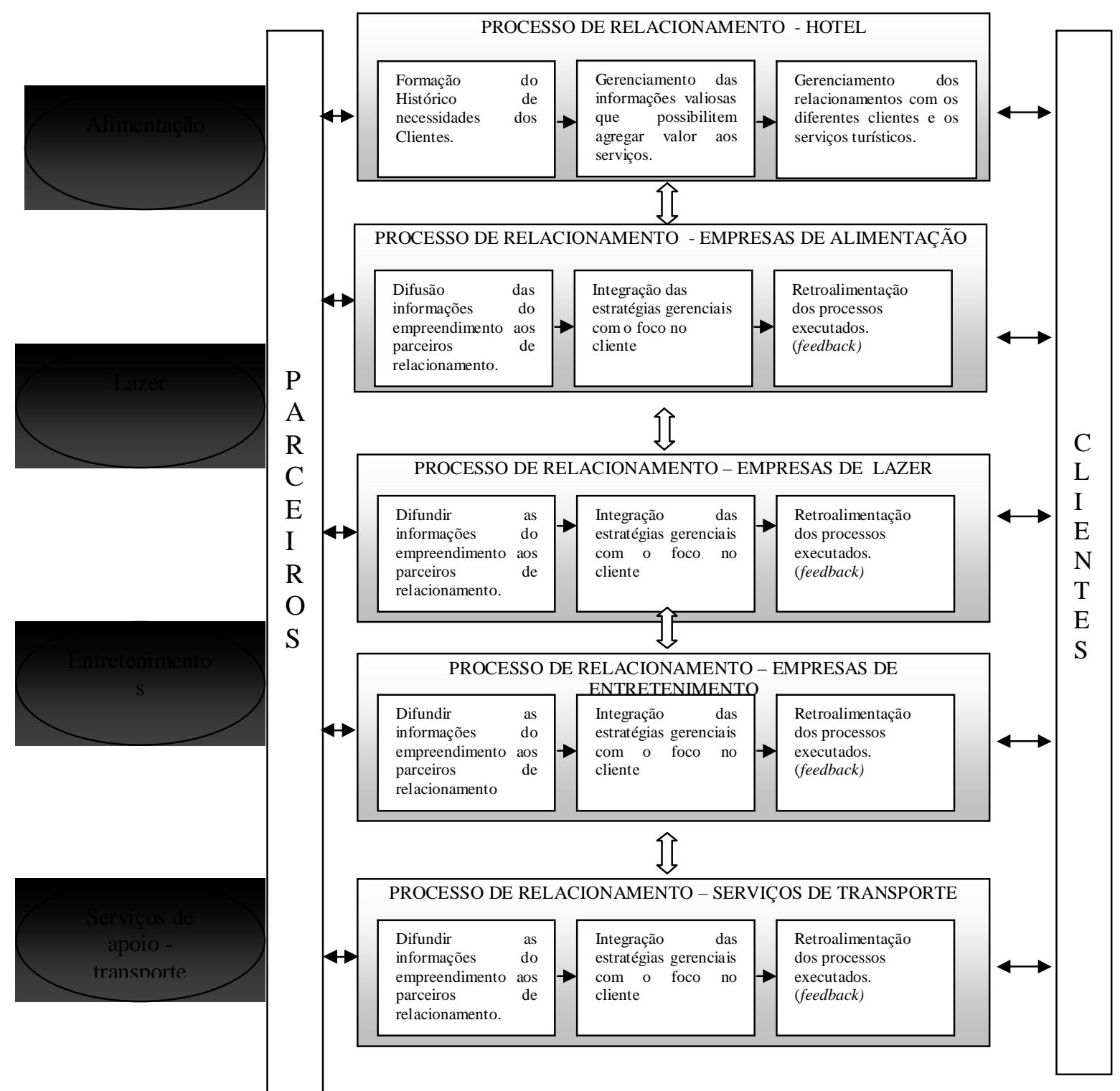

FIGURA 4: Processos da Cadeia de Relacionamento Serviços Turísticos Fonte: Autores

A atividade de difusão das informações dos empreendimentos aos parceiros de relacionamento é caracterizada pela interação das informações operacionais dos serviços oferecidos com o processo de relacionamento do hotel. A qualidade das informações difundidas é primordial para se iniciar o processo de integração.

A segunda atividade do processo de relacionamento é constituída pela integração das estratégias gerenciais com o foco no cliente. Essa atividade é caracterizada pela definição de estratégias comuns entre os parceiros. Cada estratégia desencadeada pelo hotel precisa estar acompanhada por estratégias equivalentes de seus parceiros.

A terceira atividade do processo de relacionamento é constituída pela retro alimentação dos processos executados. O feedback permite que o processo de relacionamento seja 
constantemente adaptado as condições do mercado, as necessidades dos clientes, e as exigências dos parceiros.

Os processos de relacionamento das empresas parceiras devem ter como objetivo principal aperfeiçoar o fluxo de informações, favorecendo a comunicação entre os parceiros e gerando qualidade superior dos serviços para os clientes. $\mathrm{O}$ atendimento das necessidades dos clientes por um parceiro compromete todo o processo de relacionamento. $\mathrm{O}$ benefício deste processo não se restringe apenas a uma empresa, mas a todo o conjunto.

\section{CONCLUSÃO}

Neste trabalho, a metodologia proposta pela equipe de investigação para a construção da cadeia e rede turística, utilizou como base a interface de diversas áreas de conhecimento, cujo corpo de idéias visa novas abordagens e um constante fluxo de inovações e renovação.

O modelo proposto permite que as empresas hoteleiras estejam mais próximas dos clientes. Desenvolve condições que colaboram para flexibilidade e agilidade nos processos para se adaptar de acordo com as mudanças de prioridade do cliente. Essas mudanças são características daqueles que progridem no meio competitivo dos negócios, onde procedimentos de melhoria contínua de forma eficaz são necessários. Somente implementando as melhorias nos processos e perseguido a qualidade, produtividade, custo e a satisfação do cliente, as empresas poderão resistir no mercado competitivo atual (POIRIER; REITER, 1997).

O modelo permite que a integração na rede de relacionamentos aproxime com exatidão as expectativas dos clientes e possibilite um diferencial frente aos demais destinos turísticos concorrentes,

Para o pleno êxito na implementação do SIGESTUR é necessário facilitar o fluxo de informações entre todas as atividades das empresas de forma a utilizar um web collaboration através da navegação conjunta entre os parceiros, serviços turísticos, e o hotel. A integração das informações dentro das empresas deve ocorrer de maneira a racionalizar os processos, na medida em que elimina redundância e garante a exatidão das informações distribuídas aos setores que dela necessitem.

O sistema integrado necessitará inicialmente de uma análise dos processos, treinamento efetivo dos recursos humanos das empresas envolvidas, investimentos em informática (sistemas de informação) e readequação nos métodos de trabalho.

Tal proposta possibilitará benefícios como à redução de duplicidade de informações, permitindo a entrada de informações de forma ordenada, reservas on-line do hotel e dos serviços turísticos, padronização dos sistemas de informações e melhoria no relacionamento dos hóspedes com os serviços turísticos. Enfim, a proposta busca encontrar soluções que inovem processos existentes, otimizando pessoal, recursos, tempo e informações, tão caros no atual ambiente dos negócios.

Outras pesquisas podem ser elaboradas a partir desta, objetivando aperfeiçoar o modelo proposto, seja na questão de método, em novas questões que sejam incorporadas ao universo abordado, ou em novos enfoques teóricos. Por fim, vislumbram-se estudos futuros que permitirão aprofundar a pesquisa, destaca-se: a) articulação do sistema SIGESTUR com sistemas globais de distribuição, possibilitando ampliar a aplicação do modelo; b) diagnósticos aprofundados de processos de integração em grandes redes nacionais e internacionais, ampliando e readequando o modelo proposto. 
A proposta apresentada busca oportunizar tempo e informações, tão caros no atual ambiente dos negócios através do desencadeamento de melhorias contínuas nos processos, gerando vantagens num mercado altamente competitivo.

\section{REFERÊNCIAS}

ANJOS, S. J.G. dos. Serviços Integrados no Turismo: um modelo de gestão para o setor da hotelaria. Tese de Doutorado. Universidade Federal de Santa Catarina-UFSC Programa de Pós-Graduação em Engenharia de Produção. Florianópolis, 2004.

BALlOU, R. H. Gerenciamento da cadeia de suprimentos: planejamento, organizações e logística empresarial. São Paulo: Bookman, 2001.

BENNETT, J. W; PERNSTEINER, T. E; KOCOUREK, P.F; HESLUND, S.B. Um novo modelo para implementar a estratégia. HSM Management 26 de maio-junho, 2001.

BOVET, D; MARTHA, J. Redes de valor: aumento os lucros pelo uso da Tecnologia da Informação na cadeia de valor. São Paulo: Negócio, 2001.

BOVET, D.M; THIAGARAJAN, S. Logística orientada para o cliente. HSM Management 18 de Janeiro-fevereiro, 2000.

BOWERSOX, D.J.; CLOSS, D.J. Logistical management. The integrated supply chain process. Nova York, McGraw-Hill, 1996.

CAPRA, F.As Conexões Ocultas: Ciência para uma vida sustentável. São Paulo: Cultrix, 2002.

CHEUNG, C.F., CHAN, Y.L, KWOK, S.K., LEE, W.B., WANG W.M. A knowledgebased service automation system for service logistics. Journal of Manufacturing Technology Management, v. 17, n. 6; p. 750, 2006.

DAVIS, F.W. Jr., MANRODT, K.B. Service logistics: An introduction. International

Journal of Physical Distribution \& Logistics Management, v. 24, n. 4; p. 59 -69, 1994.

DAVENPORT, T. H. Missão crítica: obtendo vantagem competitiva com os sistemas de gestão empresarial. Porto Alegre: Bookman, 2002.

FITZSIMMONS, J. A.; FITZSIMMONS, M. J. Administração de serviços: operações, estratégias e tecnologia de Informação. 2. ed. Porto Alegre: Bookman, 2000.

GERTZ, D. Crescimento $=$ foco nos clientes atuais. HSM Management 12 janeiro/fevereiro

1999.

GONÇALVES, C.A.; GONÇALVES FILHO, C.A. Tecnologia da informação e marketing: como obter clientes e mercados. Revista de Administração de Empresas. v.35, n. 4, jul/ago, 1995.

GRONROOS, C. Marketing services: the case of a missing porduct. Journal of Business \& Industrial Marketing. v. 13, n. 4/5, p. 322-338, 1998.

HAMEL, G. A obrigação. HSM Management 31 março-abril, 2002.

HAMMER, M. A empresa voltada para processos. HSM Management 9 julhoagosto,1998.

HAX, A.C; WILDE II, D.L. Modelo Delta. HSM Management 19 de março-abril, 2000.

LAUDON, K. C; LAUDON, J.P. Sistemas de informação com internet. 4. ed. Rio de Janeiro: LTC, 1999. 
LESCA, H; ALMEIDA F. C. Administração estratégica da informação. Revista de Administração. São Paulo, v.29, n.3, p.66-75, 1994.

LORGE, S. Mais clientes=as novas lições. HSM Management, 16 de setembro/outubro 1999.

MENDES FILHO, L.A.M; RAMOS, A S.M. Panorama e Impactos decorrentes da utilização da Internet na Hotelaria: Estudo De Múltiplos Casos Em Hotéis De NatalRn. XXI Encontro Nacional de Engenharia de Produção Salvador - BA, 17 a 19 de outubro de 2001. ENEGEP 2001 ABEPRO.

MENDES G.H.S; TOLEDO, J.C. Qualidade em serviços: o papel da função de desenvolvimento de novos serviços. XXII Encontro Nacional de Engenharia de Produção Curitiba - PR, 23 a 25 de outubro de 2002. ENEGEP 2001. ABEPRO

MORGAN, G. Imagens da Organização. São Paulo: Atlas, 1996.

NORMANN; R. RAMIREZ, R. From value chain to value constellations: designing interactive strategy. Harvard Business Review, July/August, 1993.

O'CONNOR, P. Distribuição da informação eletrônica em turismo e hotelaria. Porto Alegre: Bookman, 2001.

PIRES, S.R.I. Managerial implications of the modular consortium model in a Brazilian automotive plant. International Journal of Operations \& Production Management, v. 18, n.3, 221-232, 1998.

POIRIER , C.C.; REITER, S.E. Otimizando sua rede de negócios: como desenvolver uma poderosa rede entre fornecedores, fabricantes, distribuidores e varejistas. São Paulo: Futura, 1997.

PORTER, M. A vantagem competitiva das nações. Rio de Janeiro: Campus, 1996.

ROGERS, M. Os clientes. HSM Management, 9 julho-agosto, 1998.

SANCHO, A. Introdução ao Turismo. São Paulo: Roca, 2001.

SCAVARDA, L.F.R. HAMACHER, S. Evolução da Cadeia de Suprimento da Indústria Automobilística no Brasil. RAC, v.5, n. 2, p. 201-219, maio/ago., 2001.

SHANK, J. K.; GOVINDARAJAN, V. Trans-action-based costing for the complex product line: a field study. Journal of Cost Management. v. 2, n. 2, summer, 1988.

SILVA, C. F. Melhoria da qualidade em serviços: uma aplicação em hotéis. Dissertação de Mestrado em Engenharia de Produção, Florianópolis, Universidade Federal de Santa Catarina, 1999.

SLACK, N. Vantagem competitiva em manufatura. São Paulo: Atlas, 1993.

STERN, L.W. O melhor sistema de distribuição.HSM Management 3 julho-agosto 1997.

SLYWOTZKY, A. Crescimento foco no lucro. HSM Management 12 janeirofevereiro 1999.

THEOBALD, W.F. Turismo Global. São Paulo: Editora SENAC São Paulo, 2001.

VAITSMAN, H.S. Inteligência empresarial: atacando e defendendo. Rio de Janeiro: Interciência, 2001.

YIN, R.K. Estudo de caso: planejamento e métodos. 2.ed. Porto Alegre: Bookman, 2001.

\section{ABSTRACT}

In all the sectors of the economy the competition is speeding more and more every day, because technologically, organizations can reach the same level of development. Particularly in the management of services, the differential is in the strategical form of using the information, in the attainment of the competitive advantages, providing to the 
new organizations forms to surpass the performance of the competitors, transforming the chains and having as focus activities of value. This article is centered in the delimitation of a model of Integrated Management - SIGESTur, having the hotel management as the central point of the process of joint among the elements that integrate the tourism system. At first, studies deepen the thematic quarrels having as base the bibliographical analysis. At a second moment, develop a methodological proposal having as a base the bibliographical analysis and at a third moment present the considered model. For the development of the considered model, researchers used a study of a case in a Hotel of National Chain and 12 companies partners (feeding, leisure, entertainment and ways of transport), that is part of the value net. After the accomplishment of the interviews models were made to shape the processes of the net of value of the tourist services, having as a focus the identification of the existing joints among the hotel and the tourist services and finally the model SIGESTUR was developed conceptually. The results of the inquiry points about the hotel management chain of value show that the focus must be centered in an efficient flow of information and in a net of value lined up with agility among the tourist logistic partners, innovating and adding value to the offered services.

Key words: Information; Logistic; Tourism.

Originais recebidos em: 30/09/2008

Texto aprovado em: 06/11/2008 